Tsitsika, A.K., Tzavela, E.C., Janikian, M., Olafsson, K., lordache, A., Schoenmakers, T.M., Tzavara, C., Richardson, C. Online social networking in adolescence: patterns of use in six European countries and links with psychosocial functioning. Journal of Adolescent Health 2014, 55(1), 141-147

\begin{tabular}{|l|l|}
\hline $\begin{array}{l}\text { Postprint } \\
\text { Version }\end{array}$ & 1.0 \\
\hline Journal website & http://www.jahonline.org/article/S1054-139X(13)00768-4/abstract \\
\hline Pubmed link & http://www.ncbi.nlm.nih.gov/pubmed/24618179 \\
\hline DOI & $10.1016 /$ j.jadohealth.2013.11.010 \\
\hline
\end{tabular}

This is a NIVEL certified Post Print, more info at http://www.nivel.eu

\title{
Online Social Networking in Adolescence: Patterns of Use in Six European Countries and Links With Psychosocial Functioning
}

\author{
Artemis K. Tsitsika, M.D., Ph.D. ${ }^{\text {A, }}$, Eleni C. TZavela, M.SC. ${ }^{\text {A }}$, Mari Janikian, Ph.D. \\ ${ }^{\text {A }}$, KJARTAN ÓlAFSSON, M.A. ${ }^{\mathrm{B}}$, ANDREEA IORDACHE, M.SC. ${ }^{\mathrm{C}}$, TIM MICHAËL \\ Schoenmakers, Ph.D. ${ }^{\mathrm{D}}$, Chara Tzavara, Ph.D. ${ }^{\mathrm{A}}$, And Clive Richardson, Ph.D. ${ }^{\mathrm{E}}$ \\ a Adolescent Health Unit (AHU), Second Department of Pediatrics, National and \\ Kapodistrian University of Athens (N.K.U.A.), Athens, Greece \\ b University of Akureyri, Iceland and Masaryk University, Czech Republic \\ c Grigore T. Popa University of Medicine and Pharmacy, Iasi, Romania \\ d IVO Addiction Research Institute \& Erasmus Medical Center, The Netherlands \\ e Panteion University of Social and Political Sciences, Greece
}

\begin{abstract}
Purpose Online communication tools, such as social networking sites (SNS), have been comprehensively embraced by adolescents and have become a dominant daily social practice. Recognizing SNS as a key context of adolescent development, this study aimed to investigate associations between heavier SNS use, and adolescent competencies and internalizing problems.
\end{abstract}

Methods Data was collected in six European countries: Greece, Spain, Poland, the Netherlands, Romania, and Iceland. Participants were 10,930 adolescents aged 14-17 years (F/M: 5,719/5,211; mean age $15.8 \pm .7$ years); $62.3 \%$ were aged $14-15.9$ years and $37.7 \%$ were aged $16-17.9$ years. Participants reported on their use of online communication tools, and their general competencies and internalizing problems (Youth Self Report).

Results SNS are both ubiquitous - used by $70 \%$ of adolescents - and engaging, given that $40 \%$ of users spend 2 or more hours daily on SNS (labeled heavier SNS use). Heavier SNS use was associated with more internalizing problems, and the relation was consistently more pronounced among younger adolescents. Moreover, heavier SNS use was associated with lower academic performance and lower activities scores, especially for younger adolescents. In contrast, among older adolescents heavier SNS use was positively associated with offline social competence.

Conclusions Although heavier SNS use is associated with higher social competence for older adolescents, it is also associated with increased internalizing problems and diminished competencies in academics and activities, especially for younger adolescents. Age, capturing developmental 
Tsitsika, A.K., Tzavela, E.C., Janikian, M., Olafsson, K., lordache, A., Schoenmakers, T.M., Tzavara, C., Richardson, C. Online social networking in adolescence: patterns of use in six European countries and links with psychosocial functioning. Journal of Adolescent Health 2014, 55(1), 141-147

differences in social and regulatory skills, appears to moderate the effects of heavier SNS use on adolescent functioning.

Dramatic changes have taken place in how adolescents communicate. This age group has comprehensively embraced social networking sites (SNS) and other online communication tools in daily life. Recent European findings suggest that $82 \%$ of Internet-using 15-16-year-olds have an SNS profile and 56\% use SNS daily [1]. Similarly, in the United States, $82 \%$ of adolescents aged 14-17 years use SNS [2] and $53 \%$ aged $15-18$ years use SNS daily [3]. SNS use has evolved into a normative adolescent practice and integral part of social life.

\section{Social networking site affordances and adolescent social development}

The popularity of SNS can be explained by their multiple structural features - instant messaging (IM), e-mailing, blogging, sharing material, entertainment —and their boundless affordances, such as building a self-descriptive profile and maintaining a network of social connections. The ability to extend one's networks, while tailoring conditions of publicity and privacy, is among the unique features of SNS [4]. Online communication affordances are particularly fitting to adolescents' developmental needs, such as maintaining and enhancing communication with peers from everyday contexts [5], [6] and [7], reinforcing existing friendships and promoting intimacy development [8], [9] and [10], and enhancing self-esteem [10].

The supportive function of peer relationships is particularly decisive in adolescence, a time marked by socio-emotional changes. The need for intimacy and interpersonal competencies arises, time spent with peers and peer influence increases, and peer relations contribute significantly to social development and psychosocial adjustment [11] and [12]. A significant part of adolescents' interpersonal interaction now takes place online. As a result, SNS has become a key developmental context wherein adolescents express core age-related challenges and can accrue developmental benefits [9], [13] and [14], including the rehearsal of social and emotional skills such as self-disclosure [8] and [10].

\section{Online communication and internalizing problems}

Notwithstanding the developmental opportunities available online, increased use of SNS has been associated with increased online risks (e.g., getting in touch with new online contacts) [4] and [9]. Moreover, several researchers have investigated the relationship between online communication and psychosocial problems. Although earlier cross-sectional studies were inconclusive, a recent prospective longitudinal study found that IM use at baseline was correlated with more depression 6 months later [15]. Notably, in the same study, the reverse-depression predicting IM use 6 months later-could not be confirmed. The association between SNS use and internalizing problems is less clear. "Facebook depression" has been reported among adolescents who spend significant amounts of time on social media sites [14] but has not so far been confirmed among older adolescents [16] and [17]. Spending prolonged time on SNS may displace important offline activities and some adolescents who are heavily engaged online report neglecting offline social encounters, academic work, or extracurricular activities [6] and [9]. Such offline activities foster competencies and can fuel important developmental benefits [18]. Study aims, hypothesized pathway, and moderators 
Tsitsika, A.K., Tzavela, E.C., Janikian, M., Olafsson, K., lordache, A., Schoenmakers, T.M., Tzavara, C., Richardson, C. Online social networking in adolescence: patterns of use in six European countries and links with psychosocial functioning. Journal of Adolescent Health 2014, 55(1), 141-147

Although emerging empirical evidence suggests that online communication can influence adolescent psychosocial functioning, there is a scarcity of research on the postulated association between heavy SNS use, competencies, and internalizing problems. Recognizing SNS as a key context of adolescent development, the present study focused on both competencies and internalizing problems as pivotal developmental outcomes. It is important to assess both facets of functioning in adolescence: although competencies constitute protective factors for future adjustment [18], internalizing problems may hinder current functioning and future adjustment [19].

Moreover, the Internet does not affect all adolescents in the same way [20] and [21]. Gender is a dynamic social structure that may affect the relationship between online communication and personal outcomes, and, therefore, it was considered as a moderator of this relationship. Boys and girls may use the Internet differently [2], [5] and [22]. Age was also considered as a moderator, because it is a proxy for development and adolescence is a time of rapid growth. Social and developmental processes in middle adolescence differ from those in later adolescence. For example, developmental effects are evidenced in social competencies [11] and [12] and selfdisclosure skills [8]. It is crucial to identify developmental groups at risk to tailor prevention programs to their particular needs.

\section{METHODS}

\section{Participating countries and procedure}

This study formed part of a larger research project on the intensity and prevalence of internet addictive behaviour risk among minors in Europe (EU NET ADB), conducted in seven countries: Greece, Spain, Poland, Germany, the Netherlands, Romania, and Iceland. Germany was excluded from the present analysis because its data did not include psychosocial functioning. The study protocol was approved by the respective ethical committees of participating countries.

Each country drew a school-based clustered probability sample with school class (ninth and tenth grade) as the primary sampling unit. About 100 classes $(2,000$ students) were sampled in each country. Data were collected from October 2011 to May 2012. The sampling and data collection procedures are described in detail in Tsitsika et al. [23]. All students attending the selected classes who were present on the day of data collection and had provided signed parental consent were eligible to participate. Anonymous questionnaires were completed in class during school hours. In total, $85 \%$ of the students who were on the class registers participated. Of the 11,298 adolescents who completed the survey, 100 fell outside the eligible age range of 14-17.9 years. An additional 268 participants (2.4\%) were excluded because of unknown age or gender. This left a final sample of 10,930 adolescents (F/M: $5,719 / 5,211$; mean age $15.8 \pm .7$ years) for analysis.

\section{Measures}

Online communication tools. Adolescents were asked how often they used online communication tools. Response options ranged from "never" to "almost every day." Comparisons between groups were made on the "almost every day" responses (hereafter referred to as daily), which was the most prevalent category. Social networking site membership and time spent on social networking sites. Adolescents were asked whether they belonged to at least one SNS. If they did, they 
Tsitsika, A.K., Tzavela, E.C., Janikian, M., Olafsson, K., lordache, A., Schoenmakers, T.M., Tzavara, C., Richardson, C. Online social networking in adolescence: patterns of use in six European countries and links with psychosocial functioning. Journal of Adolescent Health 2014, 55(1), 141-147

were asked for how long they used SNS on a typical weekday ("normal school day") and on weekends or during vacation ("non-school day") during the past 12 months. Response options were "not at all," "about a half hour," and so on in half-hour intervals up to "more than four hours." The weighted average of weekday and weekend use provided a single estimate of daily SNS use throughout the week. The median response " 2 hours per day" was used to dichotomize the frequency of SNS into moderate SNS use ( $<2$ hours daily) and heavier SNS use ( $\geq 2$ hours daily). Internalizing problems. We used the Youth Self Report (YSR) Problem Checklist to measure internalizing behavior problems [24]. This was available in a translated and standardized version in all participating countries. Our analyses focused on the Anxious/Depressed, Withdrawn/Depressed, and Somatic Complaints syndrome scales and the broadband cluster of Internalizing problems. An example item from the first scale is: "I am self-conscious or easily embarrassed." Adolescents rate how true each item is of themselves now or within the past 6 months, using a 3-point scale $(0=$ not true, $1=$ somewhat/sometimes true, $2=$ very true/often true $)$. Raw scores were used in our analyses, with higher scores indicating more problems. Cronbach's alpha coefficients were calculated separately in each country; lowest values were .78 for Anxious/Depressed, .70 for Withdrawn/Depressed, .75 for Somatic Complaints and .77 for the clustered Internalizing Problems.

Competencies (offline).We used the YSR Activities, Social Competence, and Academic Performance scales. Activities capture the sports and hobbies that adolescents participate in, and rate time and competence in them. Social Competence assesses the number of close friends, and the frequency and quality of social interactions. ("Compared to others of your age, how well do you get along with other kids?") Raw scores were used in analysis, with higher scores indicating greater competency. Cronbach's alpha coefficients, calculated separately in each country, were acceptable for Activities (smallest in any country was .56) and for Academic Performance (smallest .64). Values for Social Competence were rather low, ranging from .24 to .44 across countries.

Statistical analysis. Chi-squared tests of independence were used to compare proportions of adolescents who used online communication. The Bonferroni correction was used for comparisons between all pairs of countries. We estimated between-group effect sizes by calculating Cohen's d. Associations between heavier SNS use and psychosocial problems and competencies were assessed by performing linear regression analyses with dependent variable each YSR subscale and independent variables SNS use, age, gender, and country. We tested the three-way interaction between SNS use, gender, and age by adding it to the regression model after first fitting the two-way interactions, and the two-way interactions by adding them to the model that included only main effects. The three-way interaction and the age-by-gender interaction were not significant in any analysis $(p>.05)$. To aid interpretation, significant age-by-SNS use interactions are presented using a coding scheme in which age and interaction effects are represented by one variable showing the age effect in heavier users (age multiplied by the indicator variable for heavier use) and another showing the age effect in moderate users (age multiplied by the indicator variable for moderate use). Similarly, for the presentation of a significant gender-by-SNS use interaction, the usual dummy variables for gender and genderby-use were replaced by one dummy variable for gender in heavier users and another for gender in moderate users. In the regressions, age was treated as a continuous 
Tsitsika, A.K., Tzavela, E.C., Janikian, M., Olafsson, K., lordache, A., Schoenmakers, T.M., Tzavara, C., Richardson, C. Online social networking in adolescence: patterns of use in six European countries and links with psychosocial functioning. Journal of Adolescent Health 2014, 55(1), 141-147

measure, but categorized (14-15.9/16-17.9 years) to facilitate the presentation of age-moderated effects.

All statistical tests, standard deviations, and confidence intervals were corrected for the complex sample design with countries as strata and classes as cluster. Reported $\mathrm{p}$ values are two-tailed. Analyses were conducted using SPSS (PASW Statistics for Windows, Version 18.0. SPSS Inc., Chicago).

\section{RESULTS}

Of the 10,930 participants, 6,805 (62.3\%) were aged $14-15.9$ years and for comparative purposes are henceforth referred to as younger adolescents. The remainder (4,125 participants; 37.7\%), aged 16-17.9 years, are referred to as older adolescents.

\section{Online communication preferences}

SNS were the most preferred online communication tool, used daily by $70 \%$ of adolescents, substantially more than the other online tools in the total sample (Table 1). However, IM was by a small margin the most popular tool in the Netherlands and Poland. SNS daily participation rates exceeded $60 \%$ in every country, ranging from $61 \%$ in Greece to $78 \%$ in Spain. Almost $92 \%$ of adolescents reported being a member of at least one SNS (Table 2). The percentage was significantly higher among girls $(\mathrm{p}<.001)$ but no difference was found between the two age groups $(\mathrm{p}=.33)$.

\section{[TABLE 1]}

\section{How common is heavier social networking site use?}

As seen in Table 2, 38\% of participants who belonged to at least one SNS spent 2 or more hours per day on SNS (hereafter referred to as heavier use) on school days, compared with $60 \%$ on non-school days. Larger proportions of girls and older adolescents engaged in heavier use compared with boys and younger ones, respectively. These group differences held for school days and non-school days alike. The prevalence of heavier SNS use was highest in Romania (44\% of SNS-using adolescents), followed by the Netherlands and Iceland (40\%), Greece (38\%), and Spain (36\%), and lowest in Poland (32\%).

\section{[TABLE 2]}

\section{Competencies and social networking site use groups}

Adolescents who engaged heavily in SNS scored significantly lower in offline Activities and Academic performance compared with adolescents who used SNS moderately (both $\mathrm{p}<.001)$. However, the effect size for Academic performance scores was small $(\mathrm{d}=.20)$ and for Activities even smaller $(\mathrm{d}=.09)$ ( Table 3$)$. Looking at the average scores for Academic performance and Activities for each age group separately, it is worth noting that differences between moderate and heavier users are indeed larger for the younger age group (Table 4). Nonetheless, in the multiple regression analyses age-by-use and gender-by-use interaction terms were not significant for offline Activities and Academic Performance (all ps > .05; Table 5). 
Tsitsika, A.K., Tzavela, E.C., Janikian, M., Olafsson, K., lordache, A., Schoenmakers, T.M., Tzavara, C., Richardson, C. Online social networking in adolescence: patterns of use in six European countries and links with psychosocial functioning. Journal of Adolescent Health: 2014, 55(1), 141-147

\section{[TABLE 3]}

\section{[TABLE 4]}

Social competence scores appeared not to differ between the two SNS use groups $(p=.46)$. However, results from multiple regression analyses showed a significant age-by-SNS use interaction $(\mathrm{p}=.008)$ for Social Competence ( Table 5). This is further illustrated in Table 4, showing slightly higher scores among heavier users than moderate users among older adolescents but not among younger ones.

Internalizing problems and social networking site use groups Heavier SNS users scored higher than moderate users on all three internalizing syndrome scales and on the consolidated Internalizing scale (Table 3). Effect sizes were small: only .09 and .15 for the Anxious/Depressed and Withdrawn syndromes, respectively, and $\mathrm{d}=.24$ for Somatic Complaints.

Besides significant main effects of SNS use, gender and age, multiple regression analyses (Table 5) identified significant age-by-use interactions for the Withdrawn syndrome $(p=.002)$ and the Internalizing cluster $(p=.03)$. The negative effect of heavier use was more pronounced in the younger age group. In addition, a significant gender-by-use interaction was found for Somatic Complaints scores $(p=.009)$; these were higher in girls than boys but more so for heavier users (mean for girls: $4.06 \pm$ 3.63 , boys: $2.43 \pm 3.09$ ) than for moderate users (mean for girls: $3.32 \pm 3.01$, boys: $2.02 \pm 2.52)$.

\section{[TABLE 5]}

\section{DISCUSSION}

This study in six European countries is one of the first to investigate online communication patterns and the psychosocial effects of heavier SNS use among adolescents, looking at both sides of the coin: competencies and problems. With 70\% of adolescents social networking daily, our study confirmed the ubiquity of SNS, which accords with adolescent online preferences across the Atlantic [2] and [3]. Online communication choices appear to be governed by local social practice. Thus IM, not SNS, was the most widely used tool in the Netherlands and Poland. Such differences may stem from local peer communication norms.

Reporting at least one SNS profile was equally common among younger and older adolescents but was more common among girls than boys. The latter is consistent with findings for U.S. adolescents [7] but conflicts with recent European findings suggesting that SNS are equally popular with both genders [1]. The gender discrepancy in SNS use in the United States starts in middle adolescence [7]. Previous European studies may have missed this trend as they focused on children up to 16 years, whereas the present investigation goes up to 17.9 years.

SNS use is not only a pervasive but also a time-engaging online activity, with $40 \%$ of adolescents spending 2 or more hours daily on SNS. Real-time status updates often prompt adolescents to connect to their preferred platforms several times daily. A recent qualitative study revealed that being "always online" is an adolescent reality, sustained by the unanimous desire to "check out" social updates on SNS [6]. Moreover, many adolescents are interested in presenting appealing SNS profiles and frequently engage in profile maintenance [25]. European adolescents may be spending considerably more time on SNS than their counterparts across the Atlantic, 
Tsitsika, A.K., Tzavela, E.C., Janikian, M., Olafsson, K., lordache, A., Schoenmakers, T.M., Tzavara, C., Richardson, C. Online social networking in adolescence: patterns of use in six European countries and links with psychosocial functioning. Journal of Adolescent Health 2014, 55(1), 141-147

given that SNS use averages 48 minutes daily among American 15- to 18-year-olds [3]. American teens may have different media use habits compared with European youth. Additionally, as media use preferences are dynamic, the discrepancy may be due to the 2-year gap between the two studies.

Our results revealed that heavier SNS use is associated with lower Academic performance and Activities scores. This is consistent with previous findings indicating that heavier use of the Internet for leisure is correlated with impaired academic performance, particularly for students who use synchronous communication applications [26]. This can be explained in terms of time spent online displacing studying. Accordingly, time is inelastic and online time displaces face-toface encounters [27]. Similarly, prolonged SNS use in adolescence might displace offline activities, such as sports, which cultivate protective experiences and can promote future adjustment [18]. On the other hand, a moderate time investment on the Internet has been shown to be associated with positive outcomes [28] and [29] and may actually be necessary or adaptive for today's adolescents, in terms of adhering to peer social norms and exploiting online learning opportunities. Notably, the negative association of heavier use with activities was more pronounced in the younger group, which is consistent with older adolescents being able to better selfregulate online use without foregoing offline activities, in line with increasingly developing cognitive and self-regulatory skills in adolescence. Self-regulation skills are closely related to excessive online use [30] and for today's adolescents facilitate the maintenance of adaptive online behavior and of balanced daily functioning across contexts (online-offline) [6].

The significant positive association between heavier use and offline social competence revealed among older adolescents conflicts with previous findings associating overuse with the neglect of face-to-face encounters [9], [26] and [27] but is consistent with the personal needs perspective, which posits that adolescents form relationships to meet compelling needs of intimacy, self-validation, and companionship [31]. Online communication may provide a context for some adolescents to get social support, safely explore peer relationships and strengthen social skills [17]. Social competence may develop though interpersonal opportunities available on SNS such as rehearsing social skills and self-disclosing to friends [8] and [10]. This process, referred to as the rehearsal hypothesis, appears to be less relevant for younger adolescents, both online and offline [8].

Heavier use was associated with higher scores on all three internalizing scales. In the case of depression, this is consistent with previous findings in adolescent populations [32] and [33]. Increased internalizing symptoms among heavier users may be explained in terms of time displaced from adaptive activities, such as physical activity that improves psychological health and has been shown to be inversely associated with depression [34]. Moreover, increased SNS use may for some adolescents displace time from potentially rewarding social offline encounters, spending it instead on communicating online with distant acquaintances or even strangers on SNS [26], which is not affectively rewarding. The association between Somatic Complaints and heavier use of SNS may also be explained in terms of time displaced from physical activity [27] and by assuming a sitting position for a prolonged time [35]. Neck-shoulder pain and low back pain increased among adolescents in the 1990s - coinciding with the increase of online technology - and Internet use beyond 2-3 hours daily has been previously associated with neck- 
Tsitsika, A.K., Tzavela, E.C., Janikian, M., Olafsson, K., lordache, A., Schoenmakers, T.M., Tzavara, C., Richardson, C. Online social networking in adolescence: patterns of use in six European countries and links with psychosocial functioning. Journal of Adolescent Health: 2014, 55(1), 141-147

shoulder pain [35]. Interestingly, our findings showed more somatic complaints among heavier-using girls, which has not to our knowledge been previously suggested.

Finally, significant age effects were revealed, with negative internalizing effects being consistently more pronounced for the younger heavier users as compared with older heavier users. This would be in line with older adolescents engaging in more intimate, and less public online communications [23], and in more self-disclosure [8]. Moreover, older adolescents endorse the view that online communication is more effective than offline communication in self-disclosing intimate information [36], and thus may be particularly facilitated on SNS. In addition, older adolescents have accumulated more online skills and communication experience, and have in general developed more interpersonal and regulatory skills [12] and [30], enabling them to handle online communication challenges (i.e., conflicts, insults) more effectively. On the contrary, younger adolescents possess less developed skills and may face difficulty in handling complex online social encounters, and in regulating negative emotions online. Overall, younger adolescents are more likely to experience depression, anger, and a variety of social and behavior problems [37].

In an attempt to consolidate the two seemingly contradictory findings-higher social competence among older heavier users and higher internalizing symptoms among younger ones - we need to consider developmental moderating processes at work. Environmental conditions may have differing effects on individuals depending on the period of development [38]; SNS may provide developmental opportunities in one age period but constitute a risk factor in another. Moreover, social skills may be the link between the two; internalizing symptoms and social skills are closely and inversely interconnected, with children who report internalizing symptoms also reporting poorer social skills and lower peer acceptance [39]. Accordingly, increased internalizing problems among heavier-using adolescents are consistent with the social skills deficit vulnerability model [40], which suggests that low social skills constitute a vulnerability to psychosocial problems.

In conclusion, our differential age effects suggest that SNS may be suboptimal communication environments for younger adolescents. This suggestion could provide a starting point for further research in designing age and privacy-restrictions governing SNS use in early adolescence.

Heavier SNS use may be associated with higher social competence for older adolescents, and with increased internalizing problems among younger adolescents. Positive effects may be explained by the opportunity to develop and practice social skills on SNS, while negative effects may relate to time displaced from physical and social offline protective activities, or undertaken among younger adolescents, whose social skills are not sufficiently developed.

Limitations and future directions

The results should be considered in view of certain limitations. First, the study is cross-sectional and as such cannot substantiate the direction of the association between heavier SNS use and psychosocial functioning. We based our hypothesis on findings of previous investigations, focusing on the direction from heavier use to psychosocial functioning. As previously suggested, the relationship could be the opposite: adolescents with psychosocial problems may be drawn to SNS and propelled toward heavy engagement. Alternatively, the relationship could be bidirectional. The directionality should be explored in future prospective longitudinal 
Tsitsika, A.K., Tzavela, E.C., Janikian, M., Olafsson, K., lordache, A., Schoenmakers, T.M., Tzavara, C., Richardson, C. Online social networking in adolescence: patterns of use in six European countries and links with psychosocial functioning. Journal of Adolescent Health 2014, 55(1), 141-147

studies. Further understanding of the mechanisms of how SNS use influences nivel psychosocial functioning calls for qualitative investigations with a focus on lived online experiences and the underlying mechanisms of impact.

\section{Acknowledgments}

Special thanks to, Elena Critselis for her contributions to the design, George Antonogeorgos for designing and supervising the sampling procedure, and to Professor Chrysa Bakoula for her valuable guidance. Parts of the contents of this manuscript are presented in the EU D6 deliverable (Chapter 3), available online (http://www.eunetadb.eu), and were presented, in part, at the 6th State of the Art Adolescent Medicine Course, on April 12, 2013 in Athens, Greece.

\section{REFERENCES}

[1]

S. Livingstone, L. Haddon, A. Görzig, et al.

Risks and safety on the Internet: The perspective of European children

EU Kids Online, London (2011)

[2]

Lenhart A, Purcell K, Smith A, et al. Social media \& mobile Internet use among teens and young adults. Available at:

http://www.pewinternet.org/ /media/Files/Reports/2010/PIP_Social_Media_and_Young_A dults_Report_Final_with toplines.pdf.

[3]

Rideout V, Foehr U, Roberts D. GENERATION M2: Media in the lives of 8- to 18-year-olds. Available at: http://www.kff.org/entmedia/8010.cfm.

[4]

E. Staksrud, K. Ólafsson, S. Livingstone

Does the use of social networking sites increase children's risk of harm?

Comput Hum Behav, 29 (2013), pp. 40-50

[5]

V. Barker

Older adolescents' motivations for use of SNS: The influence of gender, group identity, and collective self-esteem

CyberPsyh Behav, 12 (2009), pp. 209-213

[6]

M. Dreier, E. Tzavela, K. Wölfling, et al.

The development of adaptive and maladaptive patterns of Internet use among European adolescents at risk for Internet addictive behaviors: A grounded theory inquiry

EU NET ADB. National and Kapodistrian University of Athens, Athens, Greece (2013)

Available at www.eunetadb.eu

[7]

Lenhart A, Madden M. Social networking websites and teens: An overview. Available at: http://www.pewinternet.org/Reports/2007/Social-Networking-Websites-and-Teens.aspx. [8]

P.M. Valkenburg, S.R. Sumter, J. Peter

Gender differences in online and offline self-disclosure in pre-adolescence and adolescence Br J Dev Psychol, 29 (2011), pp. 253-269

[9]

K. Subrahmanyam, P. Greenfield

Communicating online: Adolescent relationships and the media

Future Child, 18 (2008), pp. 1-27

[10]

P.M. Valkenburg, J. Peter

Online communication among adolescents: An integrated model of its attraction, opportunities, and risks 
Tsitsika, A.K., Tzavela, E.C., Janikian, M., Olafsson, K., lordache, A., Schoenmakers, T.M., Tzavara, C., Richardson, C. Online social networking in adolescence: patterns of use in six European countries and links with psychosocial functioning. Journal of Adolescent Health 2014, 55(1), 141-147

J Adolesc Health, 48 (2011), pp. 121-127

[11]

B.B. Brown, J. Larson

Peer relationships in adolescence

R.M. Lerner, L. Steinberg (Eds.), Handbook of Adolescent Psychology (3rd edition), Wiley,

New York (2009), pp. 74-105

[12]

D. Buhrmester

Intimacy of friendship, interpersonal competence and adjustment during preadolescence and adolescence

Child Dev, 61 (1990), pp. 1101-1111

[13]

E.C. Tzavela, F. Mavromati

Online social networking in adolescence: Associations with development, well-being and internet addictive behaviors

International Journal of Child and Adolescent Health, s6 (2013), pp. 411-420

[14]

G.S. O'Keeffe, K. Clarke-Pearson

The impact of social media on children, adolescents, and families

Pediatrics, 127 (2011), pp. 800-805

[15]

R.J.J.M. Van den Eijnden, G.J. Meerkerk, A.A. Vermulst, et al.

Online communication, compulsive Internet use, and psychosocial well-being among

adolescents: A longitudinal study

Dev Psychol, 44 (2008), pp. 655-665

[16]

L. Jelenchick, J.C. Eickhoff, M.A. Moreno

"Facebook depression?" Social networking site use and depression in older adolescents

J Adolesc Health, 52 (2013), pp. 128-130

[17]

M.H. Selfhout, S.J.T. Branje, T.F. Delsing, et al.

Different types of Internet use, depression, and social anxiety: The role of perceived

friendship quality

J Adolesc, 32 (2009), pp. 819-833

[18]

P.L. Benson, P.C. Scales, S.F. Hamilton, A. Sesma Jr.

Positive youth development: Theory, research and applications

W. Damon, R.M. Lerner (Eds.), Handbook of Child Psychology (6th edition) (2006), pp. 894941

[19]

T.B. Kashdan, J.D. Herbert

Social anxiety disorder in childhood and adolescence: Current status and future directions

Clin Child Fam Psychol Rev, 4 (2001), pp. 37-61

[20]

J.A. Bargh, K.A. McKenna

The Internet and social life

Annu Rev Psychol, 55 (2004), pp. 573-590

[21]

P.M. Valkenburg, J. Peter

Social consequences of the Internet for adolescents: A decade of research

Curr Dir Psychol Sci, 18 (2009), pp. 1-5

[22]

M. Desjarlais, T. Willoughby

A longitudinal study of the relationship between adolescent boys and girls' computer use with friends and friendship quality: Support of the social compensation hypothesis?

Comput Hum Behav, 26 (2010), pp. 896-905

[23]

A. Tsitsika, M. Janikian, E. Tzavela, et al. 
Tsitsika, A.K., Tzavela, E.C., Janikian, M., Olafsson, K., lordache, A., Schoenmakers, T.M., Tzavara, C., Richardson, C. Online social networking in adolescence: patterns of use in six European countries and links with psychosocial functioning. Journal of Adolescent Health 2014, 55(1), 141-147

Internet use and Internet addictive behaviour among European adolescents: A crosssectional study

EU NET ADB. National and Kapodistrian University of Athens, Athens, Greece (2013) Available at www.eunetadb.eu

[24]

T.M. Achenbach, L.A. Rescorla (Eds.), Manual for the ASEBA School-Age Forms \& Profiles, University of Vermont, Research Center for Children, Youth, \& Families, Burlington, VT (2001)

[25]

S. Livingstone

Taking risky opportunities in youthful content creation: Teenagers use of social networking sites for intimacy, privacy and self-expression

New Media Soc, 10 (2008), pp. 393-411

[26]

R.W. Kubey, M.J. Lavin, J.R. Barrows

Internet use and collegiate academic performance decrements

J Commun, 51 (2001), pp. 366-382

[27]

N.H. Nie

Sociability, interpersonal relations and the Internet: Reconciling conflicting findings

Am Behav Sci, 45 (2001), pp. 420-435

[28]

R.E. Bélanger, C. Akre, A. Berchtold, et al.

A U-shaped association between intensity of Internet use and adolescent health

Pediatrics, 127 (2011), pp. 330-335

[29]

D. Romer, Z. Bagdasarov, E. More

Older versus newer media and the well-being of United States youth: Results from a national longitudinal panel

J Adolesc Health, 52 (2013), pp. 613-619

[30]

R. LaRose, C.A. Lin, M.S. Eastin

Unregulated Internet usage: Addiction, habit, or deficient self-regulation?

Media Psychol, 5 (2003), pp. 225-253

[31]

D. Buhrmester

Need fulfillment, interpersonal competence, and the developmental context of early adolescent friendship

W.M. Bukowski, A.F. Newcomb, W.W. Hartup (Eds.), The Company They Keep: Friendships in Childhood and Adolescence, Cambridge University Press, Cambridge (2009), pp. 158185

[32]

M. Hu

Will online chat help alleviate mood loneliness?

Cyberpsychol Behav, 12 (2009), pp. 219-223

[33]

M.L. Ybarra, C. Alexander, K. Mitchell

Depressive symptomatology, youth Internet use, and online interactions: A national survey J Adolesc Health, 36 (2005), pp. 9-18

[34]

X. Hong, J. Li, F. Xu, et al.

Physical activity inversely associated with the presence of depression among urban adolescents in regional China

BMC Public Health, 9 (2009), p. 148

[35]

P.T. Hakala, A.H. Rimpelä, L.A. Saarni, et al.

Frequent computer-related activities increase the risk of neck-shoulder and low back pain in adolescents 
Tsitsika, A.K., Tzavela, E.C., Janikian, M., Olafsson, K., lordache, A., Schoenmakers, T.M., Tzavara, C., Richardson, C. Online social networking in adolescence: patterns of use in six European countries and links with psychosocial functioning. Journal of Adolescent Health 2014, 55(1), 141-147

Eur J Public Health, 16 (2006), pp. 536-541

[36]

P.M. Valkenburg, J. Peter

Preadolescents' and adolescents' online communication and their closeness to friends Dev Psych, 43 (2007), pp. 267-277

[37]

J.S. Silk, L. Steinberg, A.S. Morris

Adolescents' emotion regulation in daily life: Links to depressive symptoms and problem behavior

Child Dev, 74 (2003), pp. 1869-1880

[38]

K.E. Grant, B.E. Compas, A.F. Stuhlmacher, et al.

Stressors and child and adolescent psychopathology: Moving from markers to mechanisms of risk

Psychol Bull, 129 (2004), pp. 447-466

[39]

G. O'Shea, S.H. Spence, C.L. Donovan

Interpersonal factors associated with depression in adolescents: Are these consistent with theories underpinning interpersonal psychotherapy?

Clin Psychol Psychother (Jun 26 2013)

http://dx.doi.org.ezproxy.library.wur.nl/10.1002/cpp.1849

[40]

C. Segrin

Social skills deficits associated with depression

Clin Psychol Rev, 20 (2000), pp. 379-403 
Tsitsika, A.K., Tzavela, E.C., Janikian, M., Olafsson, K., Iordache, A., Schoenmakers, T.M., Tzavara, C., Richardson, C. Online social networking in adolescence: patterns of use in six European countries and links with psychosocial functioning. Journal of Adolescent Health 2014, 55(1), 141-147

\section{TABLES}

\section{Table 1}

Percentages of adolescents who use each online communication tool almost every day, by country

\begin{tabular}{llllll}
\hline \multirow{2}{*}{ Population $\boldsymbol{\nabla}$} & \multicolumn{6}{l}{ Online communication tool $\boldsymbol{V}$} \\
\cline { 2 - 6 } & SNS (\%) & IM (\%) & Chat rooms (\%) & E-mail (\%) & Forums (\%) \\
\hline All participants & 69.5 & 50.0 & 25.8 & 22.5 & 12.6 \\
Spain & 77.7 & 50.6 & 54.6 & 16.5 & 8.2 \\
Iceland & 74.0 & 29.3 & 3.3 & 9.7 & 6.3 \\
Netherlands & 73.3 & 75.1 & 18.3 & 45.7 & 10.0 \\
Poland & 65.8 & 68.6 & 17.6 & 21.4 & 18.4 \\
Romania & 65.6 & 49.4 & 22.2 & 38.8 & 21.8 \\
Greece & 61.2 & 35.4 & 34.4 & 12.0 & 10.5 \\
\hline
\end{tabular}

For each online communication tool, the difference among all six countries is significant at $p<.001$ (Chi-squared test). SNS prevalence does not differ among Spain, Iceland, and the Netherlands ( $p>.05$ using Bonferroni correction) or among Poland, Romania, and Greece.

$\mathrm{IM}=$ Instant messaging; SNS $=$ Social networking site. 
Tsitsika, A.K., Tzavela, E.C., Janikian, M., Olafsson, K., lordache, A., Schoenmakers, T.M., Tzavara, C., Richardson, C. Online social networking in adolescence: patterns of use in six European countries and links with psychosocial functioning. Journal of Adolescent Health 2014, 55(1), 141-147

\section{Table 2}

Percentage of adolescents who belong to at least one SNS and percentage of heavier SNS users among adolescents who use SNS

\begin{tabular}{|c|c|c|c|c|}
\hline \multirow{2}{*}{$\begin{array}{l}\text { SNS use } \\
\text { Group } \boldsymbol{\nabla}\end{array}$} & \multirow[t]{2}{*}{$\begin{array}{l}\text { Member of at } \\
\text { least one SNS \% }\end{array}$} & \multicolumn{3}{|c|}{$\begin{array}{l}\text { Heavier use ( } \geq 2 \text { hours per day) among } \\
\text { adolescents who use SNS }(N=9,983)\end{array}$} \\
\hline & & $\begin{array}{l}\text { On a } \\
\text { school } \\
\text { day \% }\end{array}$ & $\begin{array}{l}\text { On a } \\
\text { non-school } \\
\text { day } \%\end{array}$ & Daily ${ }^{\mathrm{b}} \%$ \\
\hline $\begin{array}{l}\text { All participants } \\
\text { Gender }{ }^{*}\end{array}$ & 91.8 & 38.0 & 59.9 & 38.8 \\
\hline Female & 93.2 & 42.9 & 67.2 & 43.6 \\
\hline Male & 90.4 & 32.5 & 51.6 & 33.5 \\
\hline Age $^{* *}$ & & & & \\
\hline $14-15$ years & 92.2 & 35.8 & 57.9 & 36.4 \\
\hline $16-17$ years & 91.2 & 41.6 & 63.3 & 42.9 \\
\hline
\end{tabular}

a Weekends and holidays.

b Weighted average of school days and non-school days.

$* p<.001$ for difference between genders.

** $p=.33$ between age groups.

\section{Table 3}

Mean scores on YSR Competence and Problems scales, by daily level of SNS use

\begin{tabular}{|c|c|c|c|c|c|}
\hline \multirow{2}{*}{$\begin{array}{l}\text { SNS use } \\
\text { YSR subscales } \boldsymbol{\nabla}\end{array}$} & \multicolumn{2}{|c|}{$\begin{array}{l}<2 \text { hours/day } \\
\text { (moderate SNS use) }\end{array}$} & \multicolumn{2}{|c|}{$\begin{array}{l}\geq 2 \text { hours/day } \\
\text { (heavier } \\
\text { SNS use) }\end{array}$} & \multirow[t]{2}{*}{$\begin{array}{l}\text { Effect size } \\
\text { Cohen's } d\end{array}$} \\
\hline & Mean & $S D$ & Mean & $S D$ & \\
\hline \multicolumn{6}{|l|}{ Competence Scales } \\
\hline Activities & 8.33 & 3.67 & 7.99 & 3.82 & .09 \\
\hline Social Competence & 7.80 & 2.58 & 7.85 & 2.59 & .02 \\
\hline Academic Performance & 2.22 & .58 & 2.10 & .59 & .20 \\
\hline \multicolumn{6}{|l|}{ Problem scales } \\
\hline Anxious/depressed & 4.75 & 4.29 & 5.42 & 4.52 & .15 \\
\hline Withdrawn/depressed & 2.96 & 2.73 & 3.22 & 2.86 & .09 \\
\hline Somatic Complaints & 2.66 & 2.85 & 3.40 & 3.51 & .24 \\
\hline $\begin{array}{l}\text { Internalizing Problems } \\
\text { (cluster) }\end{array}$ & 10.26 & 8.15 & 11.98 & 9.17 & .20 \\
\hline
\end{tabular}


Tsitsika, A.K., Tzavela, E.C., Janikian, M., Olafsson, K., Iordache, A., Schoenmakers, T.M., Tzavara, C., Richardson, C. Online social networking in adolescence: patterns of use in six European countries and links with psychosocial functioning. Journal of Adolescent Health. 2014, 55(1), 141-147

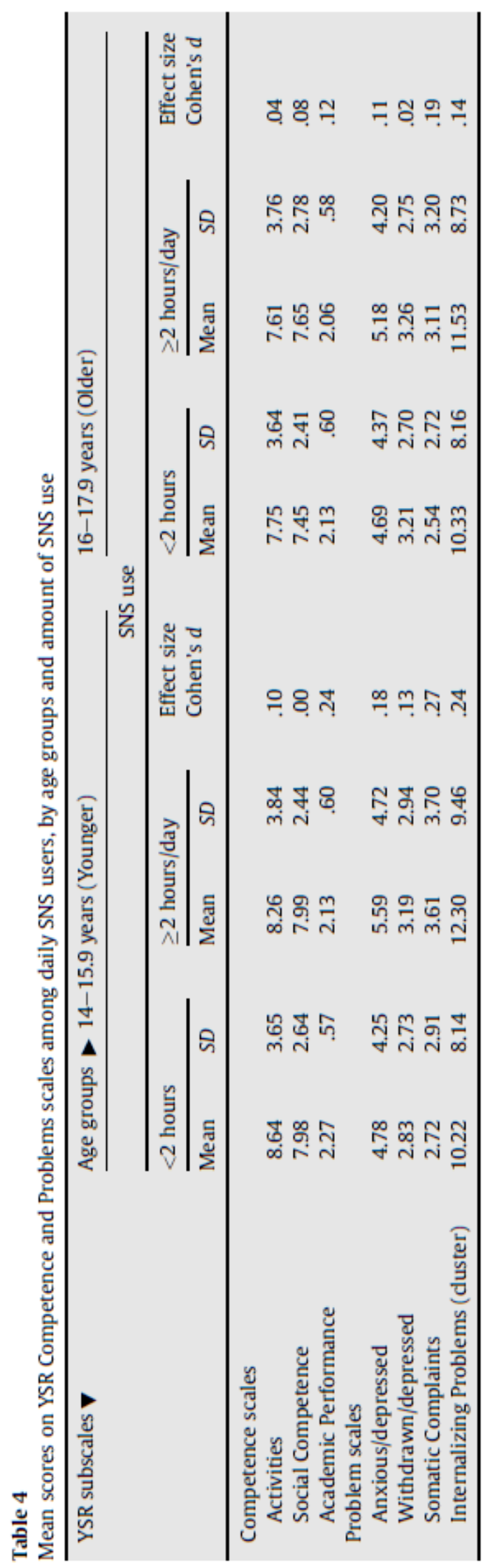


Tsitsika, A.K., Tzavela, E.C., Janikian, M., Olafsson, K., lordache, A., Schoenmakers, T.M., Tzavara, C., Richardson, C. Online social networking in adolescence: patterns of use in six European countries and links with psychosocial functioning. Journal of Adolescent Healtb2014, 55(1), 141-147

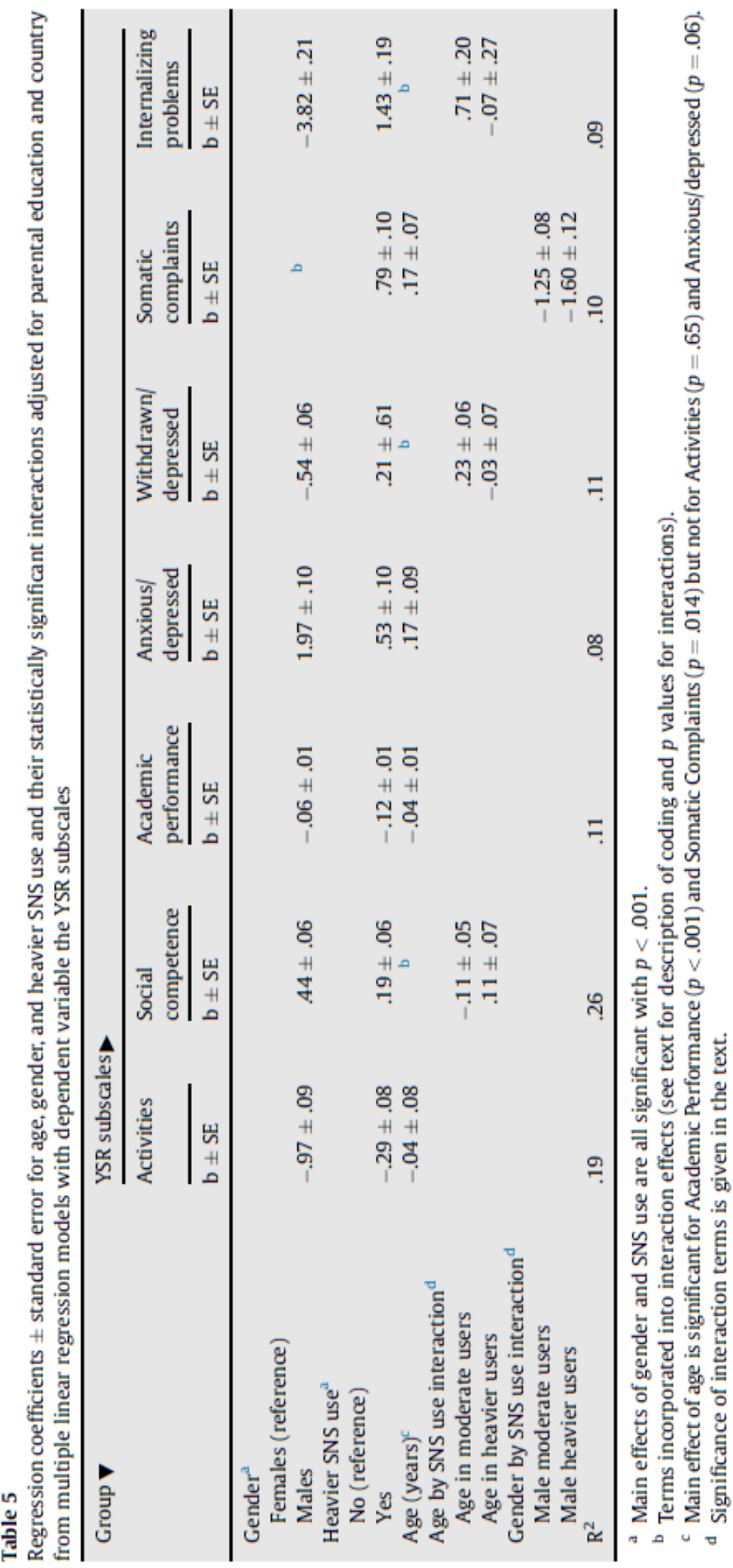

